\title{
Polymorphism in IGFBP3 gene is associated with prostate cancer risk: an updated meta-analysis
}

This article was published in the following Dove Press journal:

OncoTargets and Therapy

7 July 2016

Number of times this article has been viewed

\author{
Yunkai Qie ${ }^{1, *}$ \\ Xuewu Nian ${ }^{2, *}$ \\ Xuesen Liu ${ }^{1, *}$ \\ Hailong $\mathrm{Hu}^{\prime}$ \\ Changwen Zhang' \\ Linguo $\mathrm{Xie}^{\prime}$ \\ Ruifa Han' \\ Changli Wu' \\ Yong $\mathrm{Xu}{ }^{\prime}$ \\ 'Department of Urology, The \\ Second Hospital of Tianjin Medical \\ University, Tianjin Institute of Urology, \\ ${ }^{2}$ Department of Urology, Tianjin \\ Nankai Hospital, Tianjin, People's \\ Republic of China \\ *These authors contributed equally \\ to this work
}

Objective: Insulin-like growth factor-binding protein-3 (IGFBP3) is the major protein that binds with insulin-like growth factor-1 (IGF-1) and is considered to be involved in the development and progression of various cancers. We aimed to examine the association between prostate cancer (PCa) and the IGFBP3 gene-202A/C polymorphism.

Methods: A comprehensive search within PubMed, EMBASE, and Cochrane Library was conducted to identify all case-control studies up to October 30, 2015, for a meta-analysis. Pooled odds ratios (ORs) and the 95\% confidence intervals (CIs) were calculated using the fixed or random effects model.

Results: Eighteen studies including 10,538 cases and 10,078 controls were identified. Overall, the CC genotype of IGFBP3-202A/C polymorphism was associated with increased risk of $\mathrm{PCa}$ in homozygote comparison ( $\mathrm{CC}$ vs $\mathrm{AA}-\mathrm{OR}=1.16,95 \% \mathrm{CI}$ : $1.08-1.25)$ and in recessive model (CC vs AA+AC $-\mathrm{OR}=1.11,95 \% \mathrm{CI}: 1.04-1.17)$. In dominant model, the CC/AC genotypes also implicated an increased risk of $\mathrm{PCa}(\mathrm{CC}+\mathrm{AC}$ vs $\mathrm{AA}-\mathrm{OR}=1.11,95 \% \mathrm{CI}: 1.05-1.19)$. The $\mathrm{C}$ allele of $I G F B P 3-202 \mathrm{~A} / \mathrm{C}$ polymorphism was the risk allele for $\mathrm{PCa}$ relative to the A allele $(\mathrm{OR}=1.09,95 \% \mathrm{CI}: 1.05-1.14)$. Further stratification analysis revealed that the association between $-202 \mathrm{~A} / \mathrm{C}$ polymorphism and PCa risk among Caucasians, but not in other ethnicities, was statistically significant (recessive model, $\mathrm{OR}=1.10,95 \% \mathrm{CI}$ : 1.02-1.19). In addition, the IGFBP3-202A/C polymorphism was associated with PCa risk in both population-based and hospital-based studies in homozygote comparison, recessive model, and allele model.

Conclusion: Our meta-analysis indicates that the IGFBP3-202A/C polymorphism is associated with the risk of $\mathrm{PCa}$, particularly in Caucasians, with the $\mathrm{C}$ allele being the risk allele for PCa. Keywords: IGFBP3, polymorphism, prostate cancer, meta-analysis

\section{Introduction}

Prostate cancer ( $\mathrm{PCa}$ ) is the most commonly diagnosed internal malignancy and the second leading cause of cancer mortality for men in Western industrialized countries, and its incidence is constantly increasing. ${ }^{1}$ The mechanisms underlying the occurrence and recurrence of $\mathrm{PCa}$ are largely unknown. ${ }^{2}$ However, recent evidence suggests that polymorphic genes may be associated with $\mathrm{PCa}$ risk via modulating the effects of endogenous androgens or environmental toxicants. ${ }^{3}$

Insulin-like growth factor-binding protein-3 (IGFBP3) is the major protein that binds with insulin-like growth factor-1 (IGF-1) and limits its bioavailability. ${ }^{4}$ In addition, IGFBP3 possesses IGF-independent functions, such as inhibition of cell growth and induction of apoptosis. ${ }^{5}$ Many studies had reported the correlation between the level of circulating IGFBP3 and PCa risk, yet their outcomes are still controversial. ${ }^{6-8}$ The gene encoding IGFBP3 is located at the chromosome 7p14-p12 region ${ }^{9}$ and contains a single nucleotide polymorphism $(\mathrm{SNP})(\mathrm{A} \rightarrow \mathrm{C})(\mathrm{rs} 2854744)$ at the -202 position in the
Correspondence: Changli Wu; Yong Xu Department of Urology, The Second Hospital of Tianjin Medical University, Institute of Urology, 23 Pingjiang Road, Tianjin 3002II, People's Republic of China

Tel/fax +8622 28273211

Emailwujygc@l63.com; yxurologist@।63.com
OncoTargets and Therapy 2016:9 4I63-4I7|

Dovepress f $y$ in $\mathbf{0}$

http://dx.doi.org/10.214710TTS102452 (c) (i) (-) 2016 Qie et al. This work is published and licensed by Dove Medical Press Limited. The full terms of this license are available at https://www.dovepress.com/terms.php cc) ${ }_{\mathrm{BY}} \mathrm{NC}$ and incorporate the Creative Commons Attribution - Non Commercial (unported, v3.0) License (http://creativecommons.org/licenses/by-n/3.0/). By accessing the work you hereby accept the Terms. Non-commercial uses of the work are permitted without any further permission from Dove Medical Press Limited, provided the work is properly attributed. For permission for commercial use of this work, please see paragraphs 4.2 and 5 of our Terms (https://www.dovepress.com/terms.php). 
promoter region. Deal et $\mathrm{al}^{10}$ found that circulating IGFBP3 levels were higher when the subjects possessed at least one A allele, suggesting that the circulating IGFBP3 level might be regulated by the $-202 \mathrm{~A} / \mathrm{C}$ polymorphism. In accordance with Deal et al's finding, two independent studies also showed that the A allele of $-202 \mathrm{~A} / \mathrm{C}$ polymorphism correlates with high serum IGFBP3 levels. ${ }^{11,12}$

Although quite a few studies investigated the association between IGFBP3-202A/C polymorphism and PCa risk, ${ }^{13-23}$ the results from these studies are controversial and inconsistent, and a couple of meta-analyses have been performed to assess the risk of $\mathrm{PCa}$ associated with $I G F B P 3-202 \mathrm{~A} / \mathrm{C}$ polymorphism by using previously published case-control studies..$^{24,25}$ But their outcomes still varied leading to controversy. In light of that, a number of new cases have been added since the last comprehensive analysis, and hence we feel necessary to perform an updated meta-analysis to examine the association between the IGFBP3-202A/C polymorphism and PCa risk.

\section{Materials and methods}

\section{Literature search}

A search string that included the terms "IGFBP3", "polymorphism", and "prostate cancer" was used for reviewing the published literature until May 30, 2014, from databases PubMed, EMBASE, and Cochrane Library. In addition, studies cited in the reference lists of the identified articles were also reviewed. We checked all associated publications to retrieve the most appropriate studies. Articles were limited to English language journals and research conducted on human subjects. Studies that reported results of different subpopulations were treated as independent data. We excluded abstracts and unpublished reports. When data of the same patient population were included in more than one publication, the most recent or complete study was used for this meta-analysis.

\section{Inclusion and exclusion criteria}

To minimize heterogeneity and facilitate the proper elucidation of results, studies that met the following criteria were thought eligible: 1) information on the evaluation of IGFBP 3-202A/C polymorphism and PCa susceptibility, 2) case-control studies, 3) studies based on histologically or pathologically verified $\mathrm{PCa}$, and 4) studies with sufficient genotype data to calculate the odds ratios (ORs) with $95 \%$ confidence interval (CI). The major reasons for exclusion of studies were 1) absence of controls, 2) reviews and duplication of previously published data, and 3) studies that lacked usable data.

\section{Data extraction}

Data were systematically extracted from all eligible publications by two independent investigators (Nian and Liu). When the two investigators had disagreement, a third investigator (Qie) intervened to reach an agreement. The following criteria were considered for studies to be deemed eligible: first author's surname, year of publication, country of the trials, source of control, ethnicity, genotyping method, number of cases and controls, number of $\mathrm{PCa}$ cases and controls for the IGFBP3-202A/C genotypes (AA/AC/CC). When there were more than one populations studied in an article, we treated each of them as a single study.

\section{Statistical analysis}

The Hardy-Weinberg Equilibrium (HWE) was calculated by using the goodness-of-fit test, and a $P<0.01$ was considered as a deviation. The strength of the association between IGFBP3 polymorphism and PCa risk was assessed using crude ORs along with their corresponding 95\% CIs. We first examined rs2854744 genotype using homozygote model (CC vs AA), heterozygote model (AC vs AA), dominant model ( $\mathrm{AC}+\mathrm{CC}$ vs $\mathrm{AA})$, recessive model ( $\mathrm{CC}$ vs $\mathrm{AA}+\mathrm{AC}$ ), and allelic (C vs $\mathrm{A}$ ) model, respectively. Heterogeneity was measured using the Q-test $(P<0.05$ was considered significant) and quantified with the $I^{2}$ metric. If the $P$-value for heterogeneity was $<0.05$ or if the $I^{2}$ was $\geq 50 \%$, the random effects model was adopted to calculate the overall OR value. Otherwise, the fixed effects model was used. Stratified analyses were performed by ethnicity and source of control. Sensitivity analysis was conducted by sequential omission of individual studies to evaluate the stability of the results. Begg's funnel plot and Egger's test were performed to examine the potential influence of publication bias (linear regression analysis). An asymmetric plot was thought to suggest possible publication bias ( $P \geq 0.05$ was considered as no bias). All the analyses were done using STATA Version 11.0 (StataCorp LP, College Station, TX, USA).

\section{Results}

\section{Literature search and characteristics of the included studies}

A total of 377 studies that investigated the association of IGFBP 3 with PCa risk were identified and screened for data retrieval. As shown in Figure 1, after the exclusion of overlapping data, 353 studies were shortlisted for meta-analysis. Further, 308 papers were excluded as they were not relevant to IGFBP 3 polymorphism and $\mathrm{PCa}$, and thus 45 studies were available for further review. Of these 45 studies, 28 studies 


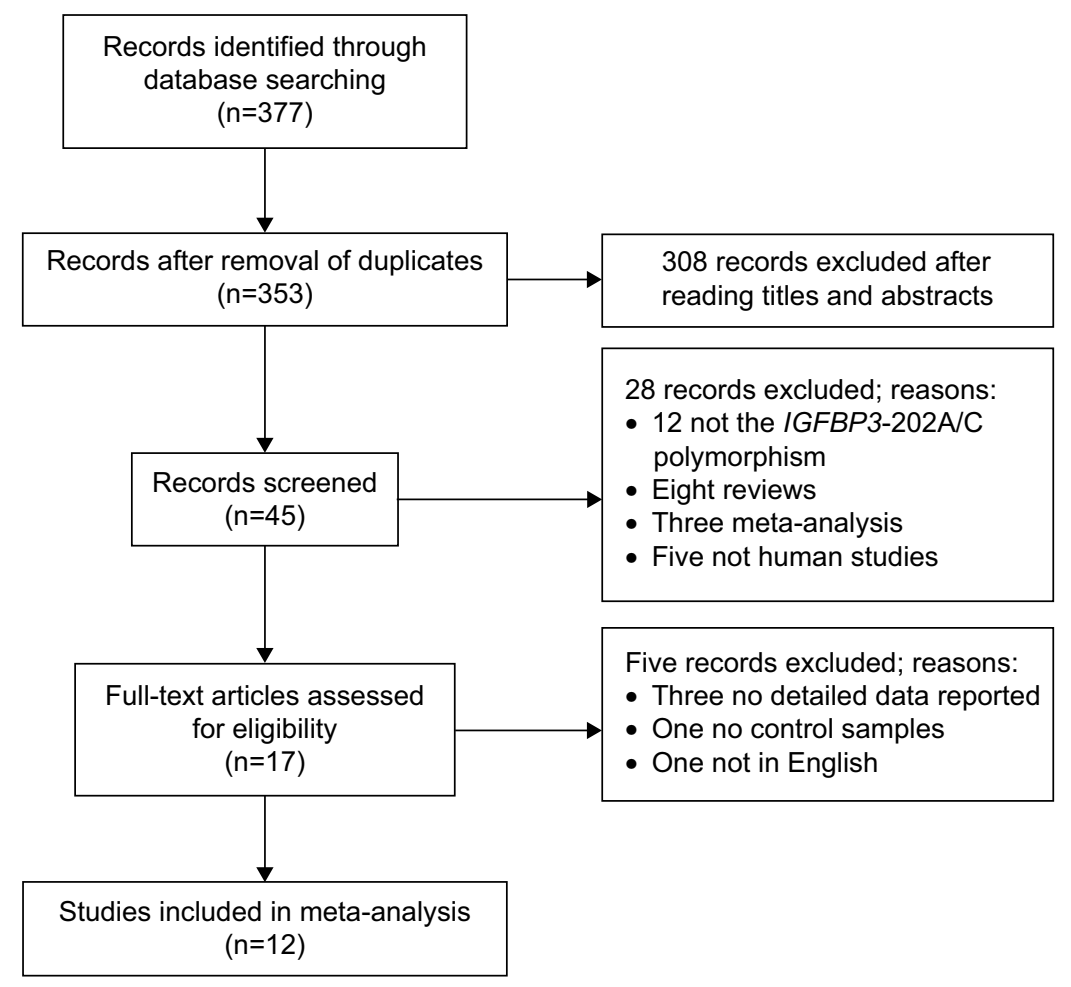

Figure I Flowchart of studies included in the meta-analysis.

were excluded because they were reviews or meta-analyses or studies, which were not conducted in human subjects or not relevant to IGFBP3-202A/C polymorphism. Among the 17 full-text papers, four studies did not provide sufficient data needed for OR calculation; one had no controls and one was not in English. We thus included 12 independent studies ${ }^{13-23,26}$ that enabled data extraction for the present meta-analysis. Since three studies ${ }^{19-21}$ had more than one subpopulation, we treated every subpopulation as an independent study. Therefore, 18 separate studies in total were available for our meta-analysis, which included 10,538 cases and 10,078 controls. The main features of these studies are summarized in Table 1 . The IGFBP3-202A/C polymorphism was reported by four studies in African Americans, four studies in Asians, six studies in Caucasians, one study in Hawaiians, and one study in Latinos. The HWE deviated $(P<0.01)$ in three studies in the control group ${ }^{15,17,19}$ and were further tested for sensitivity analysis.

\section{IGFBP3-202A/C polymorphism and $\mathrm{PCa}$ risk}

Q-test of heterogeneity was conducted for overall homozygote comparison, heterozygote comparison, dominant model, recessive model, and allele model, respectively, which turned out that $I^{2}$ value was $<50 \%$ in all these cases. Thus, a fixed effects model was used to calculate values. Overall, the CC genotype of IGFBP3-202A/C polymorphism was associated with increased risk of $\mathrm{PCa}$ in homozygote comparison (CC vs AA - OR $=1.16,95 \%$ CI: $1.08-1.25, I^{2}=28.7 \%$; Figure 2 ) and in recessive model (CC vs AA+AC - OR $=1.11,95 \%$ CI: $1.04-1.17, I^{2}=1.10 \%$; Figure 3 ). In dominant model, the $\mathrm{CC} / \mathrm{AC}$ genotypes implicated an increased risk of $\mathrm{PCa}$ $\left(\mathrm{CC}+\mathrm{AC}\right.$ vs $\mathrm{AA}-\mathrm{OR}=1.11,95 \% \mathrm{CI}: 1.05-1.19, I^{2}=28.5 \%$; Figure 4). The $\mathrm{C}$ allele of IGFBP3-202A/C polymorphism was the risk allele for $\mathrm{PCa}$ relative to the A allele $(\mathrm{OR}=1.09$, 95\% CI: $1.05-1.14, I^{2}=32.90 \%$; Figure 5).

In stratification analysis by ethnicity, we observed an increased $\mathrm{PCa}$ risk associated with the $\mathrm{CC}$ genotype of IGFBP 3-202A/C polymorphism among Caucasians in recessive model (CC vs $\mathrm{AA}+\mathrm{AC}-\mathrm{OR}=1.10,95 \% \mathrm{CI}$ : $1.02-1.19, I^{2}=42.9 \%$ ). We did not find any significant association between IGFBP3-202A/C polymorphism and $\mathrm{PCa}$ susceptibility in the other ethnicity populations. The detailed data are presented in Table 2 . When the identified studies were stratified by the source of controls (population-based or hospital-based), we observed significant association between the IGFBP3-202A/C polymorphism and PCa susceptibility with population-based studies in homozygote comparison (CC vs AA $-\mathrm{OR}=1.13,95 \%$ CI: 1.04-1.22); dominant model $(\mathrm{CC}+\mathrm{AC}$ vs $\mathrm{AA}-\mathrm{OR}=1.10,95 \% \mathrm{CI}: 1.03-1.19)$, recessive 
Table I Main features of studies included in the meta-analysis

\begin{tabular}{|c|c|c|c|c|c|c|c|c|c|c|c|c|c|}
\hline \multirow[t]{2}{*}{ Reference } & \multirow[t]{2}{*}{ Year } & \multirow[t]{2}{*}{ Country } & \multirow[t]{2}{*}{$\begin{array}{l}\text { Control } \\
\text { source }\end{array}$} & \multirow[t]{2}{*}{ Ethnicity } & \multirow[t]{2}{*}{$\begin{array}{l}\text { Genotyping } \\
\text { methods }\end{array}$} & \multirow[t]{2}{*}{$\begin{array}{l}\text { Cases/ } \\
\text { controls }\end{array}$} & \multicolumn{3}{|c|}{$\begin{array}{l}\text { rs2854744 } \\
\text { cases }\end{array}$} & \multicolumn{3}{|c|}{$\begin{array}{l}\text { rs2854744 } \\
\text { controls }\end{array}$} & \multirow[t]{2}{*}{$P_{\text {HWE }}$} \\
\hline & & & & & & & AA & AC & $\mathrm{CC}$ & AA & $A C$ & CC & \\
\hline Nam et $\mathrm{al}^{23}$ & 2003 & Canada & $\mathrm{HB}$ & Mixed & PCR-RFLP & $483 / 548$ & 135 & 233 & 115 & 145 & 274 & 129 & 0.98 \\
\hline Wang et $\mathrm{a}^{22}$ & 2003 & Japan & $\mathrm{HB}$ & Asian & PCR-RFLP & $307 / 272$ & 189 & 100 & 18 & 152 & 105 & 15 & 0.57 \\
\hline Li et $\mathrm{al}^{26}$ & 2004 & US & $\mathrm{HB}$ & Mixed & PCR-RFLP & $440 / 479$ & 97 & 217 & 126 & 139 & 225 & 115 & 0.20 \\
\hline Schildkraut et $\mathrm{a}^{21}$ & 2005 & US & $\mathrm{HB}$ & African & PCR-RFLP & $50 / 48$ & 9 & 30 & 11 & 15 & 21 & 12 & 0.40 \\
\hline Schildkraut et $\mathrm{a}^{21}$ & 2005 & US & $\mathrm{HB}$ & Caucasian & PCR-RFLP & $50 / 44$ & 9 & 25 & 16 & 8 & 20 & 16 & 0.70 \\
\hline Cheng et al ${ }^{19}$ & 2006 & US & PB & African & TaqMan & $666 / 642$ & 217 & 308 & $14 \mid$ & 224 & 298 & 120 & 0.24 \\
\hline Cheng et al ${ }^{19}$ & 2006 & US & PB & Hawaiians & TaqMan & $70 / 67$ & 22 & 36 & 12 & 24 & 33 & 10 & 0.81 \\
\hline Cheng et al ${ }^{19}$ & 2006 & US & PB & Asian & TaqMan & $455 / 466$ & 264 & 161 & 30 & 282 & $|6|$ & 23 & 1.00 \\
\hline Cheng et al ${ }^{19}$ & 2006 & US & PB & Latinos & TaqMan & $637 / 636$ & 81 & 277 & 279 & 95 & 257 & 284 & $<0.001$ \\
\hline Cheng et al ${ }^{19}$ & 2006 & US & PB & Caucasian & TaqMan & $451 / 444$ & 103 & 220 & 128 & 95 & 205 & 144 & 0.17 \\
\hline Chen et $\mathrm{al}^{20}$ & 2006 & US & PB & Caucasian & PCR-RFLP & $174 / 174$ & 43 & 73 & 58 & 37 & 84 & 53 & 0.73 \\
\hline Chen et $\mathrm{a}^{20}$ & 2006 & US & PB & African & PCR-RFLP & $38 / 38$ & 12 & 17 & 9 & 10 & 19 & 9 & 1.00 \\
\hline Hernandez et $\mathrm{a}^{18}$ & 2007 & US & $\mathrm{HB}$ & African & PCR-RFLP & $401 / 366$ & 112 & 196 & 93 & 113 & 183 & 70 & 0.79 \\
\hline Park et $\mathrm{al}^{16}$ & 2010 & Korea & $\mathrm{HB}$ & Asian & PCR-RFLP & $225 / 225$ & 128 & 76 & 21 & 140 & 76 & 9 & 0.74 \\
\hline Johansson et al ${ }^{17}$ & 2009 & Sweden & PB & Caucasian & PCR-PCR & $2,633 / 1,715$ & 891 & 439 & $\mathrm{I}, 303$ & 603 & 300 & 812 & $<0.001$ \\
\hline Schumacher et al ${ }^{15}$ & 2010 & US & PB & Caucasian & PCR-RFLP & $2,626 / 2,876$ & 724 & 556 & $\mathrm{I}, 346$ & 888 & 602 & $\mathrm{I}, 386$ & $<0.001$ \\
\hline Safarinejad et al ${ }^{14}$ & 2011 & Iran & $\mathrm{HB}$ & Caucasian & PCR-RFLP & $168 / 336$ & 23 & 85 & 60 & 89 & 163 & 84 & 0.59 \\
\hline Qian et $\mathrm{al}^{13}$ & 2014 & $\begin{array}{l}\text { People's } \\
\text { Republic } \\
\text { of China }\end{array}$ & $\mathrm{HB}$ & Asian & TaqMan & $664 / 702$ & 31 & 225 & 408 & 32 & 246 & 424 & 0.63 \\
\hline
\end{tabular}

Abbreviations: HB, hospital-based; HWE, Hardy-Weinberg equilibrium; PB, population-based; PCR-RFLP, polymerase chain reaction-restriction fragment length polymorphism.

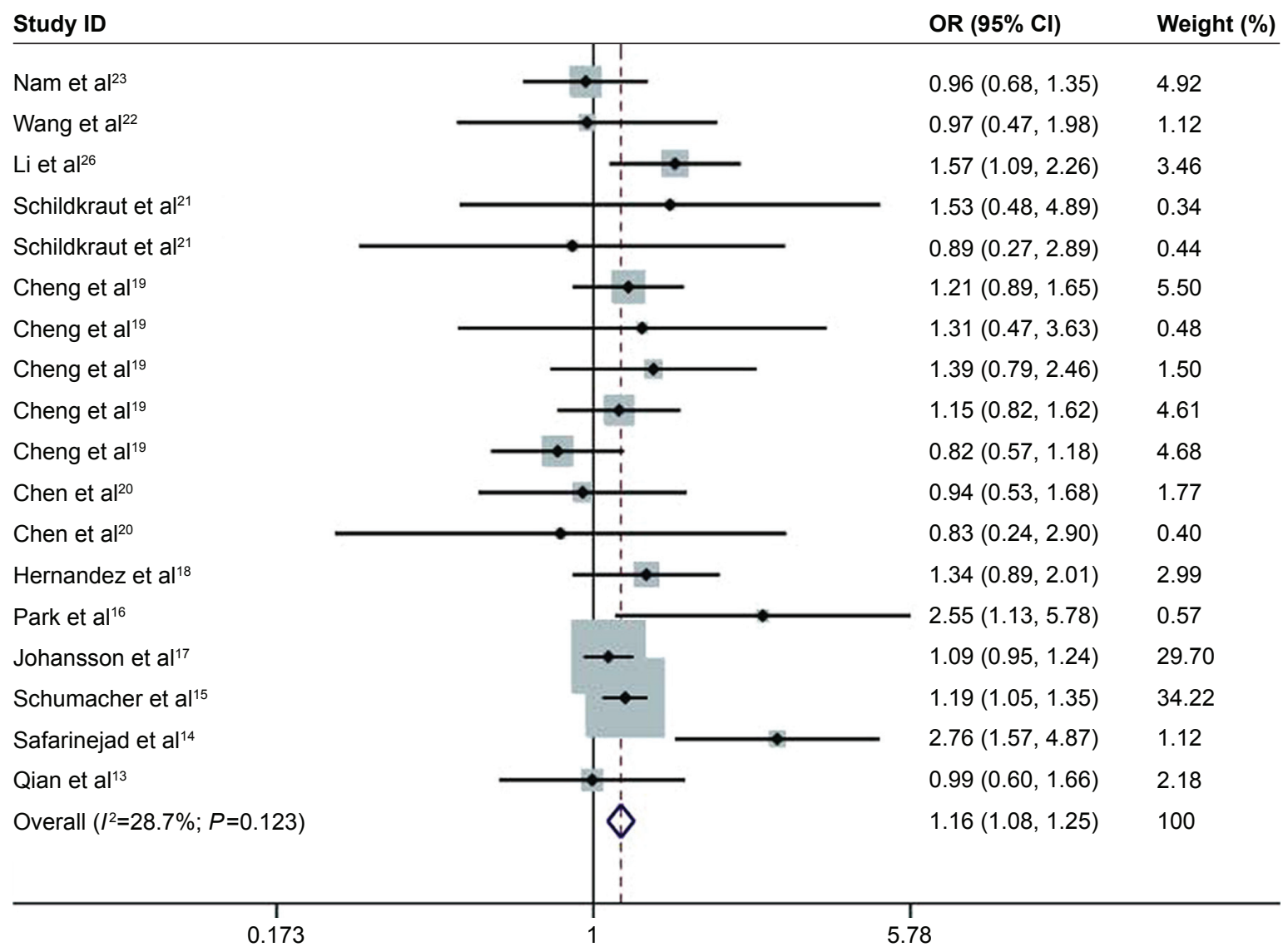

Figure 2 Forest plot of odds ratios with 95\% confidence interval for IGFBP3-202A/C polymorphism and risk of prostate cancer risk under recessive model (CC vs AA). Abbreviations: IGFBP3, insulin-like growth factor-binding protein-3; OR, odds ratio; Cl, confidence interval. 


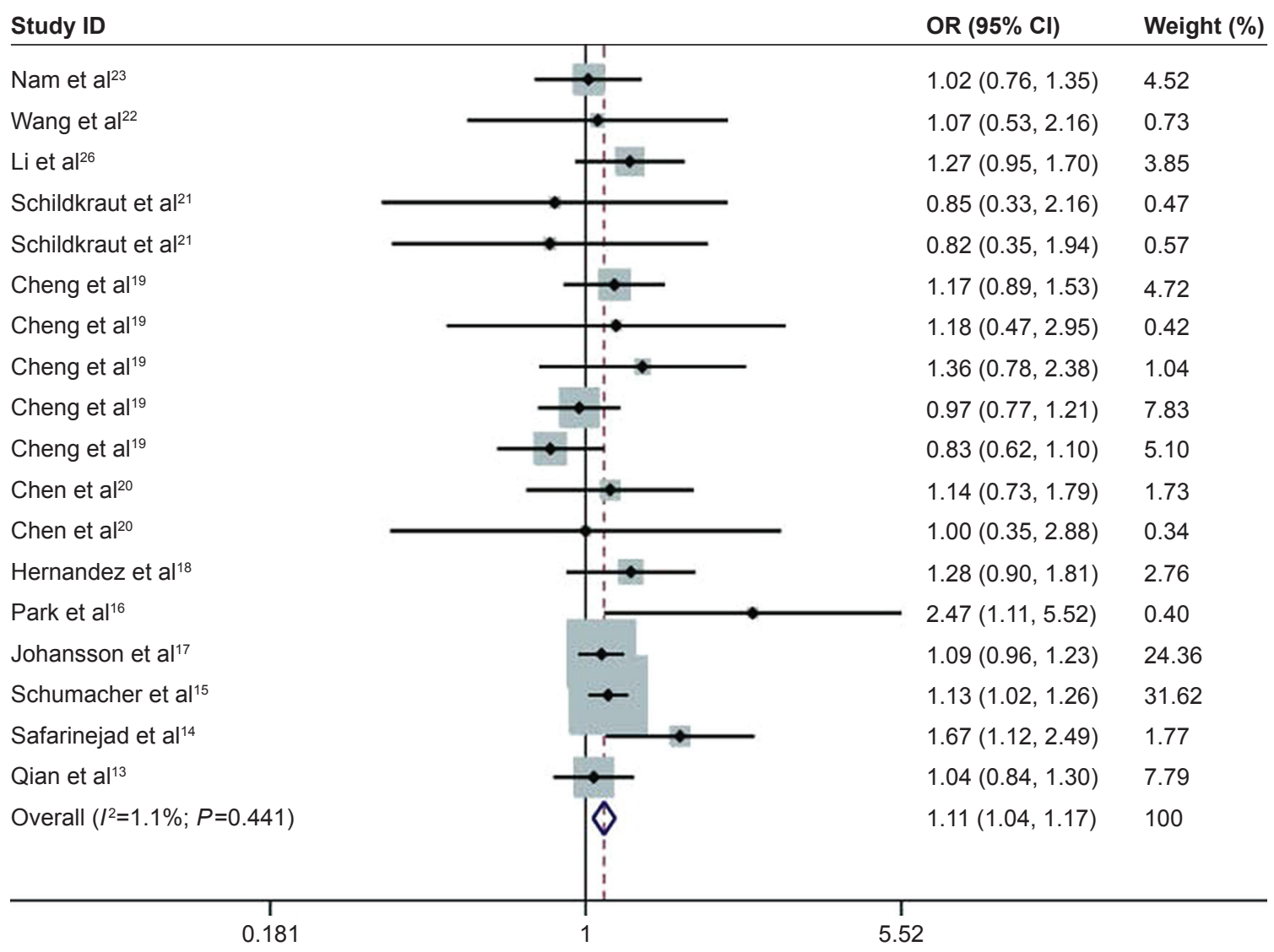

Figure 3 Forest plot of odds ratios with $95 \%$ confidence interval for IGFBP3-202A/C polymorphism and risk of prostate cancer risk under recessive model (CC vs $A A+A C)$.

Abbreviations: IGFBP3, insulin-like growth factor-binding protein-3; OR, odds ratio; $95 \% \mathrm{Cl}$, $95 \%$ confidence interval.

model ( $\mathrm{CC}$ vs $\mathrm{AA}+\mathrm{AC}-\mathrm{OR}=1.09,95 \% \mathrm{CI}: 1.01-1.16$ ), and allele model (C vs A - OR $=1.08,95 \%$ CI: 1.04-1.14). For hospital-based studies, significant association between the IGFBP3-202A/C polymorphism and PCa susceptibility existed in homozygote comparison ( $\mathrm{CC}$ vs $\mathrm{AA}-\mathrm{OR}=1.33$, 95\% CI: $1.13-1.58$ ), recessive model (CC vs AA+AC OR $=1.17,95 \%$ CI: 1.03-1.32), and allele model (C vs $\mathrm{A}-\mathrm{OR}=1.13,95 \% \mathrm{CI}: 1.00-1.29)$.

\section{Sensitivity analysis}

Sensitivity analyses were done by sequential omission of all subjects and subgroups from each study. The statistical significance of the results did not change, although the genotype distributions of the control group in the three studies did not follow HWE (Figure 6). Hence, this suggested that the data of our meta-analysis were relatively stable and credible.

\section{Publication bias}

Begg's funnel plot and Egger's linear regression tests were performed to assess the possibility of potential publication bias. For all genetic models, the shape of the funnel plots was symmetrical, and Egger's test showed no evidence of significant publication bias $(P>0.05)$, suggesting that there was no apparent publication bias in this meta-analysis (Figure 7).

\section{Discussion}

In this meta-analysis, we systematically investigated the relationship between IGFBP3-202A/C polymorphism and PCa risk based on 10,538 cases and 10,078 controls. Overall, the IGFBP3-202A/C polymorphism was associated with $\mathrm{PCa}$ risk, with the carriers of $\mathrm{C}$ allele and $\mathrm{CC}$ genotype of this SNP being more susceptible to PCa. In stratification analysis, the SNP was found to be associated with PCa risk in Caucasians, but not statistically significant in other ethnicities. With regard to the source of controls, the association of the SNP with PCa risk was also observed for hospital-based studies and population-based studies.

Recently, two meta-analyses have reported the correlation between the IGFBP3-202A/C polymorphism and $\mathrm{PCa}$ risk, but there are many differences between their outcomes. The study by Mao et al, ${ }^{25}$ including 9,238 cases and 8,741 controls, revealed that $I G F B P 3$ A-202C polymorphisms seemed 


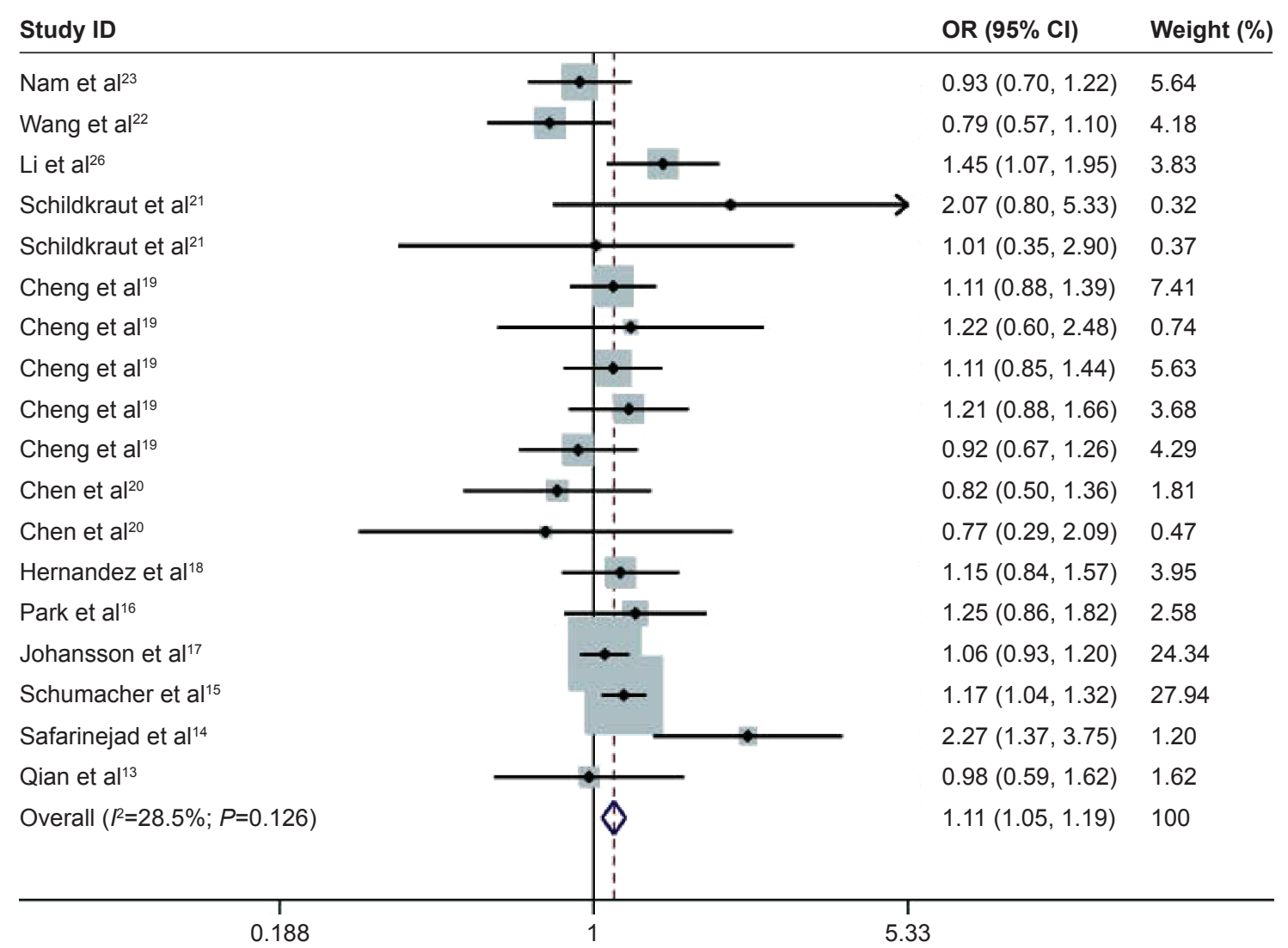

Figure 4 Forest plot of odds ratios with $95 \%$ confidence interval for IGFBP3-202A/C polymorphism and risk of prostate cancer risk under recessive model (CC+AC vs AA). Abbreviations: IGFBP3, insulin-like growth factor-binding protein-3; OR, odds ratio; Cl, confidence interval.

to increase the risk of PCa, but the effect was not significant. The meta-analysis by Ding et al, ${ }^{24}$ which was based on 4,602 PCa cases and 4,880 controls from 16 case-control studies, found a significant association between IGFBP3 A-202C polymorphisms and $\mathrm{PCa}$ risk. Moreover they got different conclusions about the association between IGFBP3-202A/C polymorphism and $\mathrm{PCa}$ risk in race subgroup comparisons. Mao et $\mathrm{a}^{25}$ reported that the association of $-202 \mathrm{~A} / \mathrm{C}$ polymorphism with $\mathrm{PCa}$ risk was observed only in Caucasians in the heterozygous codominant model (OR $=1.14,95 \% \mathrm{CI}$ : 1.05-1.24). In contrast, Ding et $\mathrm{al}^{24}$ reported that the IGFBP3202A/C polymorphism was associated with a significantly decreased risk of PCa in Asians, but not in Europeans or African Americans. In addition, the meta-analysis by Mao et $\mathrm{al}^{25}$ and Ding et $\mathrm{al}^{24}$ both included a relatively small sample size. Our meta-analysis included the most subjects which may provide the most comprehensive evidence for association of IGFBP3-202A/C polymorphism with $\mathrm{PCa}$ risk.

In our meta-analysis, with the most $\mathrm{PCa}$ cases and controls up to date, we found that the $\mathrm{CC}$ genotype of IGFBP3-202A/C polymorphism was associated with increased risk of $\mathrm{PCa}$ in homozygote comparison, dominant model, and recessive model, and the $-202 \mathrm{C}$ allele is the risk factor for $\mathrm{PCa}$. In the subgroup analysis by ethnicity, the association of IGFBP3-202A/C polymorphism with $\mathrm{PCa}$ risk was evident only in Caucasians under the recessive model (CC vs AA+AC - OR =1.10, 95\% CI: 1.02-1.19). This result is in accordance to that reported by Mao et al, ${ }^{25}$ but incongruent with Ding's study. ${ }^{24}$ This discrepancy could result from the possible genetic differences among ethnicities, even distinct populations of the same ethnicity. In addition, the environment factors may also contribute to the discrepancy. Moreover, we realized that the Asian subgroup in our meta-analysis included more cases and controls than did the counterpart in Ding et al's study. The different sample sizes in Asian people might lead to different conclusions between our meta-analysis and that of Ding et al.

After stratification by source of controls, the association between IGFBP3-202A/C polymorphism and PCa risk was observed in hospital-based studies and population-based studies. Because some individuals from the control group might develop cancer in subsequent years, even if they showed no clinical symptoms at the time of investigation, 


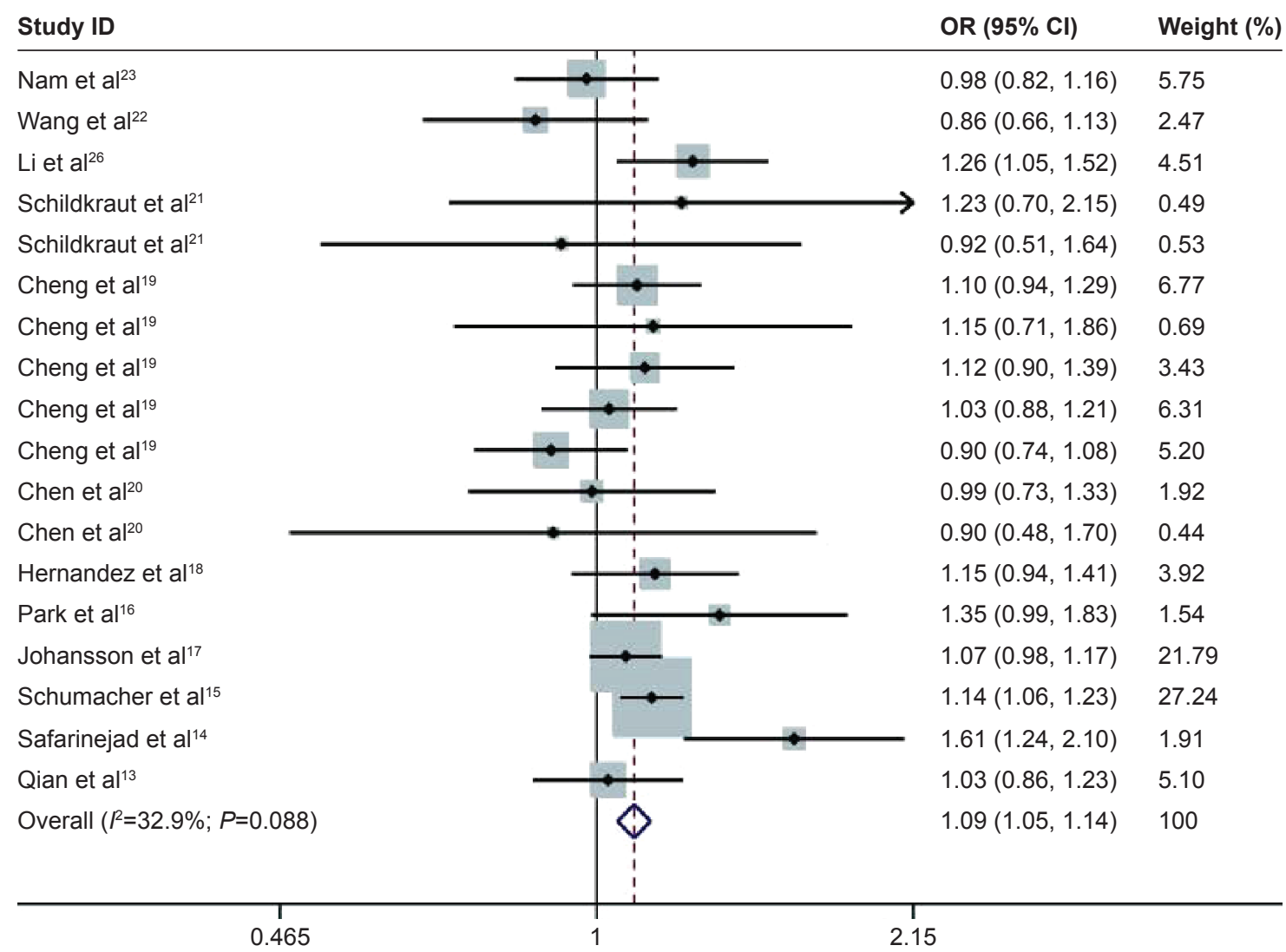

Figure 5 Forest plot of odds ratios with 95\% confidence interval for IGFBP3-202A/C polymorphism and risk of prostate cancer risk under recessive model (C vs A). Abbreviations: IGFBP3, insulin-like growth factor-binding protein-3; OR, odds ratio; Cl, confidence interval.

and misclassification bias can cause a deviation in the genotype distribution among the controls, the results should be interpreted with caution.

In the present meta-analysis, the potential publications were systematically searched and reviewed. The reliability of the results was further confirmed by sensitivity analysis. Therefore, with the larger sample size than ever before, results from meta-analysis are solid and convincing.

However, our study had some limitations. First, our results were based on unadjusted estimates. More accurate analysis may be achieved with the adjustment of confounders such as age, body mass index, smoking status, drinking status, and environment factors. ${ }^{27}$ Second, subgroup analyses

Table 2 Summary of odds ratios (95\% confidence interval) and $I^{2}$ value for prostate cancer in IGFBP3-202A/C genetic model

\begin{tabular}{|c|c|c|c|c|c|c|c|c|c|c|}
\hline \multirow[t]{2}{*}{ Variables } & \multicolumn{2}{|l|}{ CC vs AA } & \multicolumn{2}{|l|}{ CC vs AC } & \multicolumn{2}{|l|}{$C C+A C$ vs $A A$} & \multicolumn{2}{|l|}{$C C$ vs $A A+A C$} & \multicolumn{2}{|l|}{ C vs $\mathrm{A}$} \\
\hline & OR (95\% Cl) & $I^{2}(\%)$ & OR $(95 \% \mathrm{Cl})$ & $I^{2}(\%)$ & OR (95\% Cl) & $I^{2}(\%)$ & OR (95\% Cl) & $I^{2}(\%)$ & OR (95\% Cl) & $I^{2}(\%)$ \\
\hline \multicolumn{11}{|c|}{ Control sources } \\
\hline $\mathrm{HB}$ & $1.33(1.13-1.58)$ & 49.10 & I.I3 (0.99-I.29) & 0.00 & $1.18(0.96-1.46)^{\mathrm{a}}$ & 57.10 & $1.17(1.03-1.32)$ & 20.00 & $1.13(1.00-1.29)^{\mathrm{a}}$ & 54.60 \\
\hline PB & 1.13 (1.04-1.22) & 0.00 & $1.04(0.96-1.13)$ & 0.00 & $1.10(1.03-1.19)$ & 0.00 & $1.09(1.01-1.16)$ & 0.00 & $1.08(1.04-1.14)$ & 0.00 \\
\hline \multicolumn{11}{|l|}{ Ethnicity } \\
\hline Mixed & $1.22(0.75-1.98)^{\mathrm{a}}$ & 73.50 & I.09 (0.88-I.36) & 0.00 & $1.15(0.75-1.78)^{\mathrm{a}}$ & 78.20 & I.I3 (0.92-I.39) & 12.20 & $1.11(0.86-1.42)^{\mathrm{a}}$ & 74.90 \\
\hline Asian & $1.27(0.93-1.72)$ & 31.00 & I. $14(0.94-1.39)$ & 15.00 & $1.02(0.86-1.2 I)$ & 20.50 & I.I4 (0.94-I.37) & 34.50 & $1.06(0.95-1.19)$ & 38.70 \\
\hline African & I.25 (0.99-I.58) & 0.00 & I. $14(0.92-1.42)$ & 0.00 & $1.14(0.95-1.36)$ & 0.00 & I.I8 (0.96-I.45) & 0.00 & $1.12(0.99-1.26)$ & 0.00 \\
\hline Caucasian & $1.14(0.94-1.40)^{\mathrm{a}}$ & 64.50 & $1.06(0.96-1.17)$ & 0.00 & $1.12(0.94-1.32)^{\mathrm{a}}$ & 58.10 & $1.10(1.02-1.19)$ & 42.90 & $1.10(0.97-1.23)^{\mathrm{a}}$ & 66.10 \\
\hline Hawaiian & I.3। (0.47-3.63) & NA & I. $10(0.42-2.88)$ & NA & $1.22(0.60-2.48)$ & NA & I. $18(0.47-2.95)$ & NA & I.I5 (0.7I-I.86) & NA \\
\hline Latino & I.I $15(0.82-1.62)$ & NA & $0.91(0.72-1.16)$ & NA & I.2I (0.88-I.66) & NA & $0.97(0.77-1.21)$ & NA & I.03 $(0.88-\mid .2 I)$ & NA \\
\hline Overall & $1.16(1.08-1.25)$ & 28.70 & I.07 (0.99-I.I5) & 0.00 & I.II (I.05-I.I9) & 28.50 & I.II (I.04-I.I7) & 1.10 & $1.09(1.05-1.14)$ & 32.90 \\
\hline
\end{tabular}

Notes: aRandom-effects estimate. Bold values indicate $P<0.05$, which was statistically significant.

Abbreviations: $\mathrm{Cl}$, confidence interval; OR, odds ratio; PB, population-based; HB, hospital-based; IGFBP3, insulin-like growth factor-binding protein-3; NA, not applicable. 


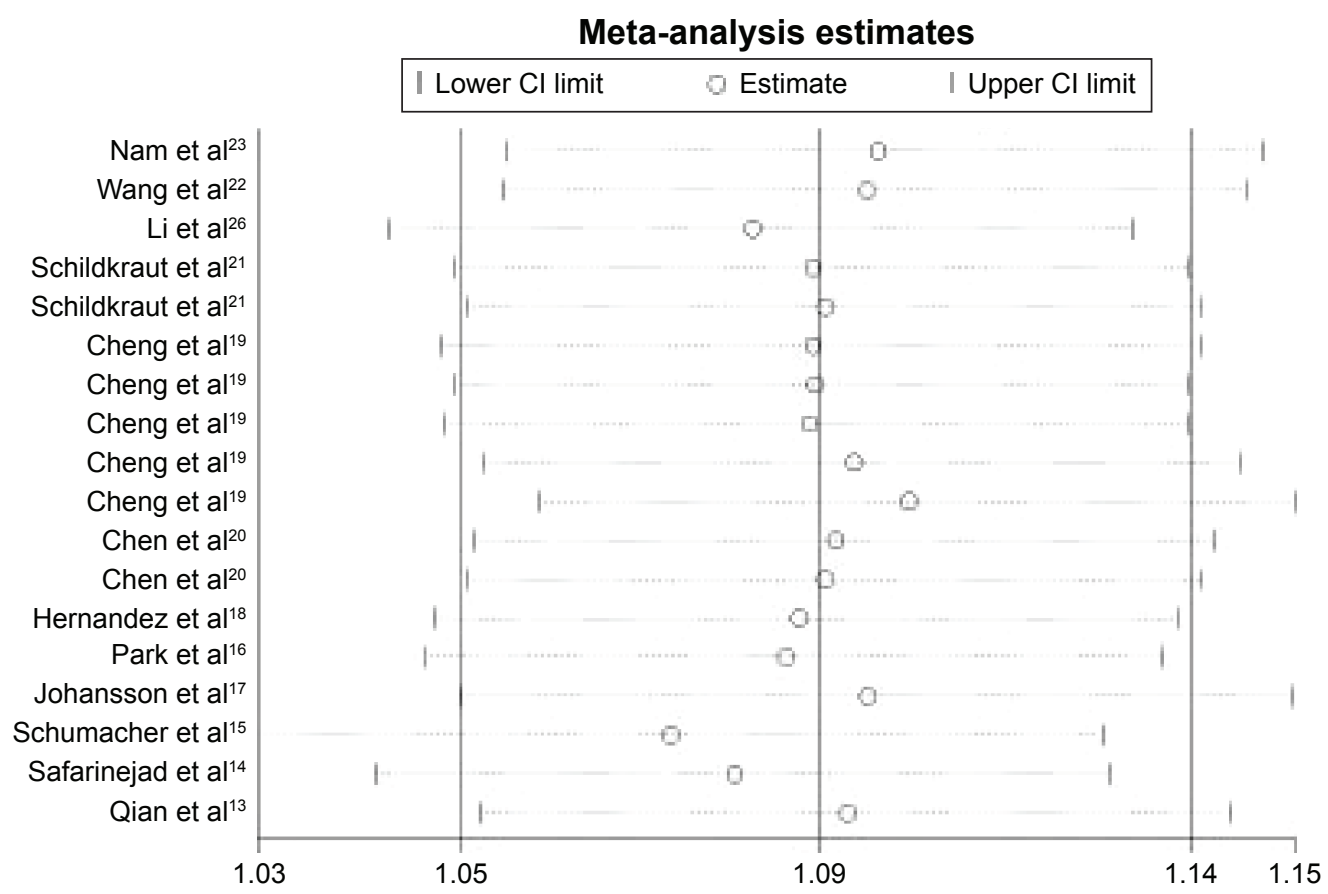

Figure 6 Summary of sensitivity analyses of the odds ratio coefficients and the association between the IGFBP3-202A/C polymorphism and risk of prostate cancer under allele model (A vs C).

Abbreviations: IGFBP3, insulin-like growth factor-binding protein-3; $\mathrm{Cl}$, confidence interval.

stratified by age, sex, and other factors were not done in the present study, because relevant data were unavailable from the primary publications for meta-analysis. Third, our analysis might overlook the possibility of gene-gene or SNP-SNP interactions or linkage disequilibrium between polymorphisms. Moreover, this gene polymorphism association has not been associated with PCa-specific mortality, which is a much more clinically useful association if it is

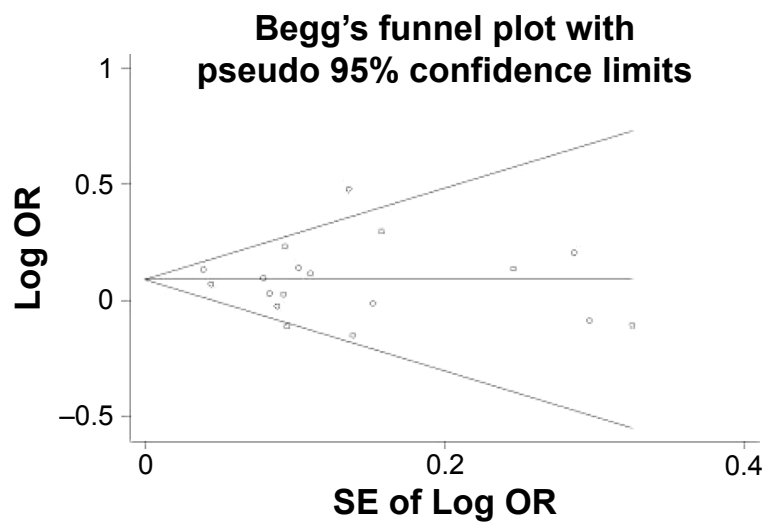

Figure 7 Publication bias represented by Begg's funnel plot for the association between the IGFBP3-202A/C polymorphism and risk of prostate cancer under allele model ( $A$ vs $C$ alleles).

Note: Each point represents a separate study for the indicated association.

Abbreviations: IGFBP3, insulin-like growth factor-binding protein-3; OR, odds ratio; SE, standard error. to be used in any form of screening or general clinical risk stratification. Further investigations on the haplotype effect of a gene and the study of multiple polymorphisms in different genes within the same pathway and different pathways are expected.

\section{Conclusion}

This meta-analysis suggests that IGFBP $3-202 \mathrm{~A} / \mathrm{C}$ polymorphism is associated with the risk of $\mathrm{PCa}$, particularly in Caucasians, suggesting that IGFBP3-202A/C polymorphism could be a marker for $\mathrm{PCa}$ development. Additional large-scale studies are warranted to provide a more definitive conclusion on the association between IGFBP3-202A/C polymorphism and $\mathrm{PCa}$ risk in distinct ethnicity populations.

\section{Acknowledgments}

This study was supported in part by the National Natural Science Foundation of China (number 81472416) and the Tianjin Municipal Science and Technology Commission (number 12ZCDZSY16600).

\section{Disclosure}

The authors report no conflicts of interest in this work. 


\section{References}

1. Hsing AW, Tsao L, Devesa SS. International trends and patterns of prostate cancer incidence and mortality. Int J Cancer. 2000;85(1):60-67.

2. Yoshida T, Nakayama M, Takeda K, Arai Y, Kakimoto K, Nishimura K. External validation of the cancer of the prostate risk assessment score to predict biochemical relapse after radical prostatectomy for prostate cancer in Japanese patients. Urol Int. 2012;89(1):45-51.

3. Bosland MC. Sex steroids and prostate carcinogenesis: integrated, multifactorial working hypothesis. Ann N Y Acad Sci. 2006;1089: 168-176.

4. Clemmons DR, Dehoff ML, Busby WH, Bayne ML, Cascieri MA. Competition for binding to insulin-like growth factor (IGF) binding protein-2, 3, 4, and 5 by the IGFs and IGF analogs. Endocrinology. 1992; 131(2):890-895.

5. Silha JV, Sheppard PC, Mishra S, et al. Insulin-like growth factor (IGF) binding protein-3 attenuates prostate tumor growth by IGFdependent and IGF-independent mechanisms. Endocrinology. 2006; 147(5):2112-2121.

6. Harman SM, Metter EJ, Blackman MR, Landis PK, Carter HB; Baltimore Longitudinal Study on Aging. Serum levels of insulin-like growth factor I (IGF-I), IGF-II, IGF-binding protein-3, and prostate-specific antigen as predictors of clinical prostate cancer. $J$ Clin Endocrinol Metab. 2000;85(11):4258-4265.

7. Nimptsch K, Platz EA, Pollak MN, et al. Plasma insulin-like growth factor 1 is positively associated with low-grade prostate cancer in the Health Professionals Follow-up Study 1993-2004. Int J Cancer. 2011 128(3):660-667.

8. Roddam AW, Allen NE, Appleby P, et al. Insulin-like growth factors, their binding proteins, and prostate cancer risk: analysis of individual patient data from 12 prospective studies. Ann Intern Med. 2008;149(7):461-471, W83-W88

9. Costalonga EF, Antonini SR, Guerra-Junior G, et al. The -202 A allele of insulin-like growth factor binding protein-3 (IGFBP3) promoter polymorphism is associated with higher IGFBP-3 serum levels and better growth response to growth hormone treatment in patients with severe growth hormone deficiency. $J$ Clin Endocrinol Metab. 2009;94(2):588-595.

10. Schernhammer ES, Hankinson SE, Hunter DJ, Blouin MJ, Pollak MN. Polymorphic variation at the -202 locus in IGFBP3: influence on serum levels of insulin-like growth factors, interaction with plasma retinol and vitamin D and breast cancer risk. Int J Cancer. 2003;107(1):60-64.

11. Ehrenborg E, Larsson C, Stern I, Janson M, Powell DR, Luthman H. Contiguous localization of the genes encoding human insulin-like growth factor binding proteins 1 (IGBP1) and 3 (IGBP3) on chromosome 7. Genomics. 1992;12(3):497-502.

12. Deal C, Ma J, Wilkin F, et al. Novel promoter polymorphism in insulin-like growth factor-binding protein-3: correlation with serum levels and interaction with known regulators. J Clin Endocrinol Metab. 2001;86(3):1274-1280.

13. Qian J, Zhou H, Chen J, et al. Genetic polymorphisms in IGF-I and IGFBP-3 are associated with prostate cancer in the Chinese population. PLoS One. 2014;9(2):e85609.
14. Safarinejad MR, Shafiei N, Safarinejad S. Relationship of insulin-like growth factor (IGF) binding protein-3 (IGFBP-3) gene polymorphism with the susceptibility to development of prostate cancer and influence on serum levels of IGF-I, and IGFBP-3. Growth Horm IGF Res. 2011;21(3):146-154.

15. Schumacher FR, Cheng I, Freedman ML, et al. A comprehensive analysis of common IGF1, IGFBP1 and IGFBP3 genetic variation with prospective IGF-I and IGFBP-3 blood levels and prostate cancer risk among Caucasians. Hum Mol Genet. 2010;19(15):3089-3101.

16. Park K, Kim JH, Jeon HG, Byun SS, Lee E. Influence of IGFBP3 gene polymorphisms on IGFBP3 serum levels and the risk of prostate cancer in low-risk Korean men. Urology. 2010;75(6):1516.e1-1516.e7.

17. Johansson M, McKay JD, Rinaldi S, et al. Genetic and plasma variation of insulin-like growth factor binding proteins in relation to prostate cancer incidence and survival. Prostate. 2009;69(12):1281-1291.

18. Hernandez W, Grenade C, Santos ER, Bonilla C, Ahaghotu C, Kittles RA. IGF-1 and IGFBP-3 gene variants influence on serum levels and prostate cancer risk in African-Americans. Carcinogenesis. 2007;28(10):2154-2159.

19. Cheng I, Penney KL, Stram DO, et al. Haplotype-based association studies of IGFBP1 and IGFBP3 with prostate and breast cancer risk: the multiethnic cohort. Cancer Epidemiol Biomarkers Prev. 2006; 15(10):1993-1997.

20. Chen C, Freeman R, Voigt LF, Fitzpatrick A, Plymate SR, Weiss NS. Prostate cancer risk in relation to selected genetic polymorphisms in insulin-like growth factor-I, insulin-like growth factor binding protein-3, and insulin-like growth factor-I receptor. Cancer Epidemiol Biomarkers Prev. 2006;15(12):2461-2466.

21. Schildkraut JM, Demark-Wahnefried W, Wenham RM, et al. IGF1 (CA)19 repeat and IGFBP3-202 A/C genotypes and the risk of prostate cancer in Black and White men. Cancer Epidemiol Biomarkers Prev. 2005;14(12):403-408.

22. Wang L, Habuchi T, Tsuchiya N, et al. Insulin-like growth factor-binding protein- 3 gene $-202 \mathrm{~A} / \mathrm{C}$ polymorphism is correlated with advanced disease status in prostate cancer. Cancer Res. 2003;63(15):4407-4411.

23. Nam RK, Zhang WW, Trachtenberg J, et al. Comprehensive assessment of candidate genes and serological markers for the detection of prostate cancer. Cancer Epidemiol Biomarkers Prev. 2003;12(12): 1429-1437.

24. Ding Q, Shi Y, Fan B, Wang J. IGFBP-3 promoter polymorphism $-202 \mathrm{~A}>\mathrm{C}$ (rs2854774) contributes to prostate cancer risk: evidence based on 9,482 subjects. Urol Int. 2014;93(1):100-107.

25. Mao YQ, Xu X, Lin YW, et al. Prostate cancer risk in relation to a single nucleotide polymorphism in the insulin-like growth factor-binding protein-3 (IGFBP3) gene: a meta-analysis. Asian Pac J Cancer Prev. 2012;13(12):6299-6303.

26. Li L, Cicek MS, Casey G, Witte JS. No association between genetic polymorphisms in IGF-I and IGFBP-3 and prostate cancer. Cancer Epidemiol Biomarkers Prev. 2004;13(3):497-498.

27. Engeland A, Tretli S, Bjorge T. Height, body mass index, and prostate cancer: a follow-up of 950000 Norwegian men. Br J Cancer. 2003; 89(7):1237-1242.
OncoTargets and Therapy

\section{Publish your work in this journal}

OncoTargets and Therapy is an international, peer-reviewed, open access journal focusing on the pathological basis of all cancers, potential targets for therapy and treatment protocols employed to improve the management of cancer patients. The journal also focuses on the impact of management programs and new therapeutic agents and protocols on

\section{Dovepress}

patient perspectives such as quality of life, adherence and satisfaction. The manuscript management system is completely online and includes a very quick and fair peer-review system, which is all easy to use. Visit http://www.dovepress.com/testimonials.php to read real quotes from published authors. 